\title{
Suarez and the Problem of External Sensation
}

\author{
JAMES B. SOUTH \\ Marquette University
}

To best understand the key problem facing any Aristotelian theory of sensation, one would be wise to turn to the words of Jonathan Lear:

The task is to show how some part of the world-ourselves and other animals_can become conscious of the rest of the world. The danger is that we make the account of the transition from world to mind either too material or too spiritual. If, on the one hand, we give a purely material account of, say, the physical change that a certain visual scene (a tree) forms in the eye of the perceiver, we seem to leave consciousness out of the account. It remains unclear how, by such a physical change, one is meant to get out of the nonconscious physical world. On the other hand, if we give a totally spiritual account, it is not clear that we have given an account of a transition, for it is not clear that we have begun in a thoroughly nonconscious world. ${ }^{1}$

In this article I will demonstrate Francisco Suárez's coherent and powerful method for addressing Lear's concerns. I will outline Suárez's account against the background of Aquinas's theory of sensation, emphasizing those areas where Suárez believes that Aquinas's theory falls short of Lear's ideal. I argue that the main changes he makes to the thomistic theory of sensation are designed to reinforce what he sees as Thomas's main weakness. Moreover, I will show that the view set forth by Suárez is both coherent and powerful in its own right, providing a direct realist view of sensation while allowing for internal representations.

I want to thank the editor and an anonymous reviewer of this journal for helpful comments on an earlier version of this article. The original version was read at the Midwest Seminar in Ancient and Medieval Philosophy in Fall 1997 where my colleagues Owen Goldin, Richard C. Taylor, and David Twetten provided feedback. Finally, my thanks to Edward P. Mahoney who read my first thoughts on these topics several years ago, saved me from many errors, and has generously continued to provide me with advice and encouragement.

1. Jonathan Lear, Aristotle: The Desire to Understand (Cambridge: Cambridge University Press, 1988), p. 108. 
I will begin by briefly outlining the key components of sensory cognition according to Aquinas. It should be noted that I am only concerned here with the problem of external sensation. Accordingly, I cannot delve into his theory of the internal senses. Also, by way of a preface, it is useful to remember that Thomas believes that while one commonly speaks of senses sensing, it is, in fact, more accurate to state that the human person senses.

While this statement is no doubt true, for my purposes, namely, discussing the micro-level steps in the sensory process, I will frequently resort to predicating sensing of sense powers as a kind of shorthand. My justification for this approach is Thomas's position that the sense powers are really distinct from the human soul. ${ }^{2}$ Accordingly, it seems permissible to consider their micro-level processes at a level of detail that omits consideration of the niceties of his complex account of the human composite. In what follows, I cannot hope to argue for an interpretation of Thomas's account of external sensation. Instead I shall merely stipulate what I take to be an accepted, but by no means universally so, interpretation. While I think this stipulated interpretation neatly captures the essential features of Thomas's view, it also accords with the way that Suárez reads him. It is important to note that Suárez uses Thomas's terminology throughout his own discussion. Of course, it is not exclusively Thomas's vocabulary that he uses, as it was, by Suarez's time, a common vocabulary. As I will show, this common vocabulary can hide rather pronounced differences in thought.

Finally, I want to foreground the most important way in which Suárez's account differs from that of Aquinas. Thomas states that "there is some cognitive power that knows only by receiving not by forming something from what is received."3 His example is external sensation and he contrasts it with both internal sensation and intellectual cognition. The latter two cognitive powers not only involve receptive aspects, but also active aspects that he captures by the language of "forming" and he denies any such activity to the external sense power. Suárez rejects this disanalogy between external sensation and the other forms of cognition. It is here that one finds the crucial disagreement between Suárez's account and that of Thomas. First, though, it will be helpful to spell out the basics of Thomas's account and bring out the common terminology and concerns they share.

The characteristics of immanence and passivity are at the core of Thomas's account of sensation. The first accounts for the fact that a sensation is mine while the second certifies the objectivity of sensory experience. By stressing immanence, Thomas points to the fact that sensing is an activity

2. See, for example, Summa Theologiae I, q. 77, a. 5; Quaestiones de anima, q. 19. For discussion, see S. M. Cohen, "St. Thomas on the Immaterial Reception of Forms," The Philosophical Review 41 (1982): 195-97.

3. De veritate q. 8, a. 5: "Est enim aliqua cognoscitiva potentia quae cognoscit tantum recipiendo non autem aliquid ex receptis formando." This passage has been highlighted by Robert Pasnau, Theories of Cognition in the Later Middle Ages (Cambridge: Cambridge University Press, 1997), pp. 144-45. 
that remains within the agent and contrasts such actions with those that do not remain within the agent. He calls the latter transitive actions. The paradigm instance of such transitive actions is the way in which fire heats water. ${ }^{4}$ It follows that a sense power, being potential, must be made actual in a rather different way than water is heated by fire. After all, we do not receive the tree within us when we sense it. Consequently, we need some intermediary that can be received within us and activate, as it were, a sense power so that it can perform sensory acts. These intermediaries are called "species" and they play a crucial role in his account of sensation. ${ }^{5}$

The passivity involved in sensation is pervasive at least to the extent that there can be no sensation without the activity of the external sensible object. The ability to sense is, in fact, a "passive power" (potentia passiva) that requires the presence of some sensible object in order for it to act. ${ }^{6}$ The result is that there is a structural dependence between sense powers, their characteristic immanent activities and their proper objects. What this means is that sense powers are what they are because of the nature of their proper objects. So, for example, eyes must be organized the way they are and must see the way that they do because the objects of sight are structured in a certain way. ${ }^{7}$ Again, Thomas assigns to the sensible species the work of mediating to the passive sense power the actuality of the existing external object.

The exact status and nature of the species is a difficult topic, since Thomas himself rarely discusses the sensible species and the passages in which he does so seem to show a marked nonchalance about their nature.

4. Summa theologiae I, q. 54, a. 2. For a discussion of the two types of activity in Thomas and other references to the distinction in Thomas and Aristotle, see the helpful account in Joseph Owens, An Elementary Christian Metaphysics (Milwaukee: Bruce, 1963), pp. 192-204.

5. Summa theologiae I, q. 14, a. 2. The literature on the notion of cognitive species in Thomas is vast. For some helpful introductions, see G. Picard, "Essai sur la connaissance sensible d'après les scolastiques," Archives de philosophie 4 (1926): 1-93; G. van Riet, "La théorie thomiste de la sensation externe," Revue philosophique de Louvain 51 (1953): 374-408; B. J. Lonergan, Verbum: Word and Idea in Aquinas (Notre Dame: University of Notre Dame Press Press, 1967), pp. 128-33, 158-81; A. Wilder, "On the Knowing Species in St. Thomas: Their Necessity and Epistemological Innocence," Angelicum 68 (1991): 3-32. L. Spruit, Species Intelligibilis: From Perception to Knowledge Vol. 1: Classical Roots and Medieval Discussions (Leiden: E. J. Brill, 1994), pp. 156-74. Spruitt, in chapters 1 and 2, also provides a helpful overview of the development of the notion of a cognitive species.

6. Summa theologiae I, q. 78, a. 3 Thomas also accepts that each sense performs a kind of judgment about its proper objects. The nature of this judgment, though, is rather obscure, and appears to have two meanings: one essentially equivalent to awareness, and another corresponding to a kind of second level awareness that one is sensing. For discussion, see Pasnau who considers several passages where Thomas talks about judgment and concludes that it in no way contradicts the essential passivity of sensory experience (Theories of Cognition, 140-42).

7. For the way in which the object, act and power are related, see Summa theologiae I, q. 78, a. 3; Qaestiones De anima q. 13; Sentencia libri De anima II.5. 
However, it is possible to extract from his scattered remarks a rather coherent view of their nature and function in the process of sensation. To begin, Thomas explains that all cognition is through form and this form is the principle of cognition in the knower ${ }^{8}$ so that in sense cognition, the required form is a sensible form. ${ }^{9}$ This sensible form exists naturally in the external object but needs somehow to be at the same time immanent in the sense power of the person sensing. Thomas, taking his cue from Aristotle, argues that the sensible form in the object comes to exist in the sense power by losing its matter. ${ }^{10}$ Consequently, rather than the sensible form itself acting on the sense power, a species or likeness (similitudo) of the sensible form alters the sense power. In his most precise formulation, Thomas states that the alteration effected by the sensible species causes an "intention" (intentio) of the sensible form to arise in the sense power. ${ }^{11}$

I do not want to linger over the sensible form in the object itself for to inquire into its nature would lead into the details of Aristotelian physics. ${ }^{12}$ Instead, I want to focus on the species as it exists in both the mediumroughly the area between the external object and the sense power-and in the sense power itself. It is in the description of the species in the medium and in the sense power that we can see crucial similarities with Suárez's account as well as some important differences. What differentiates the species from the sensible form itself? First and foremost, according to Thomas, the two species have a different sort of being (esse) than the sensible form in the object. The latter has natural being, while the former have intentional or spiritual being. The first question one faces, consequently, is how intentional being and natural being differ. Thomas invokes the distinction between a seal and wax to elucidate the distinction between these two types of beings. When a gold seal is pressed into wax, the wax takes on the shape of the seal, but not its matter. ${ }^{13}$

8. De veritate, q. 10 , a. 4.

9. Summa theologiae I, q. 78, a. 3.

10. Summa theologiae I, q. 14, a. 1; Summa theologiae I, q. 78, a. 3; Quaestiones De anima q. 13; Sentencia libri De anima II. 12.

11. The notion of "intentio" in Thomas is complex. For discussion, see H. D. Simonin, "La notion d'intentio dans l'oeuvre de S. Thomas d'Aquin," Revue des sciences philosphiques et théologiques 19 (1930): 445-63; J. Rohmer, "L'intentionnalité des sensations de Platon à Ockham," Revue des sciences religieuses 25 (1951): 5-39; A. Lisska, "Axioms of Intentionality in Aquinas' Theory of Knowledge," International Philosophical Quarterly 16 (1976): 305-22; R. Sorabji, "From Aristotle to Brentano: The Development of the Concept of Intentionality," in Oxford Studies in Ancient Philosophy, supplementary volume, 1991: Aristotle and the Later Tradition, ed. H. Blumenthal and H. Robinson (Oxford: Clarendon Press, 1991), pp. 27-59.

12. For a discussion of these sensible forms in material objects, see Van Riet, "La théorie thomiste," pp. 383-86 and the additional bibliography he cites there. For Thomas' description of these sensible forms, see Summa theologiae I, q. 78, a. 3 ad 1; and Sentencia libri De anima, lect. 13, n. 384 and n. 394.

13. Sentencia libri De anima II, 24, $169 \mathrm{~b}$. 
This example is rather helpful in demystifying what could otherwise be a very mysterious assertion on Thomas's part. Despite what one might initially think when encountering the adjectives "spiritual" and "intentional," he is not saying that the sensible species is immaterial in the way in which one uses the term today to denote that which has no connection to matter at all. ${ }^{14}$ Just as there is nothing mysteriously immaterial about the impression of a seal on wax, there is nothing mysterious about the way that sensible form communicates itself in the medium or to the sense power. The communication of the sensible form in the medium is a communication of form, but not, thereby, immaterial. In other words, the distinction that is important is one between natural and spiritual actions, not between material and immaterial

14. The terms "material," "immaterial" and "physical" are potentially opaque. First of all, we do not live in Thomas' intellectual universe and our senses of the terms are rather different from his. When we say that something is material, we mean that it is made up of matter. If we understand "material" in this sense, it follows that for Aquinas all form must be immaterial since form and matter are really distinct. So, when I say that sensible species are material, I do not mean that they are only matter. They are quite obviously form. Nonetheless, it would be misleading to call sensible species "immaterial" since for us immaterial objects are those which have no material status at all. Such is not the case with sensible species since they are forms attached to matter. When I say that the sensible species is material, then, I do not mean that it is only physical, but rather that it remains a form attached to matter, or, in other words, that the sensible species is not immaterial in the way in which we use the term today. Robert Pasnau has argued effectively that Aquinas opts for a "wholly physical" account of sensation by which he means that it involves an intentional alteration of a wholly physical sense organ (Theories of Cognition, pp. 31-47). The use of the term physical here is meant to capture only the fact that the species and the activity of sensation are not immaterial in our sense of the term, but rather are intentional alterations as opposed to natural ones, where intentional alterations are nonetheless corporeal ones. While this article was in press, Myles Burnyeat published an important article on Thomas and "spiritual change." I cannot do justice to all the points he raises, but he does state: "But for Aquinas, that spiritual change (perceptual awareness) is itself a kind of bodily change." (Myles Burnyeat, "Aquinas on 'Spiritual Change' in Perception," in Ancient and Medieval Theories of Intentionality, ed. Dominik Perler [Leiden: Brill, 2001], pp. 129-53.) While much of what Burnyeat argues strikes me as correct, I am worried that he never takes full measure of the difference between Aristotelian cognitive form and Thomas's adoption of the language of sensible species in which species are not identical to the form existing in the sensible object, but are images and likenesses of that form. For discussion, see E. P. Mahoney, "Sense, Intellect, and Imagination in Albert, Thomas, and Siger," in The Cambridge History of Later Medieval Philosphy, ed. N. Kretzmann, A. Kenny, J. Pinborg, and E. Stump (Cambridge: Cambridge University Press, 1982), pp. 605-6 and the copious references provided there. Claude Pannacio has emphasized correctly the representational nature of the cognitive species, in contrast to formal identity. Regrettably, he does not talk about sensation in this context, but he mistakenly attributes an indirect realism to Thomas when he fails to note that Thomas changed his mind about the nature of the concept (Claude Pannacio, "Aquinas on Intellectual Representation," in Ancient and Medieval Theories of Intentionality, pp. 185-202). See note 61 below for details of Thomas's change of mind, accurately noted by Suárez. 
ones. ${ }^{15}$ Further, just as a gold seal cannot mark a hard surface, so, too, sensible forms need the proper conditions under which to communicate their likenesses. The medium is the perfect such condition. Air (or water) is "diaphanous," and, as such, is almost purely passive. Hence, the communication of form is perfective rather than a case of ordinary change in which one form is replaced with another. ${ }^{16}$ The medium takes up the form without thereby taking on the "matter" of the sensible form itself. After all, the air does not turn green around a tree, just as the wax does not become gold. ${ }^{17}$

At this point, one must ask: Why does the medium not sense inasmuch as it receives the same intentional form as the sense power? ${ }^{18}$ The answer to this question lies at the heart of the dispute between Suárez and Aquinas. Thomas can answer the question only by stating that sensation takes place when the species is received in a properly functioning sense organ. Because the medium is not such a sense organ, sensation does not take place there.

15. There has been burgeoning interest in the question of the physicality of sensible species in recent years ranging from those who find the species to be immaterial, in our modern sense of the term, to those who argue that the sensible species is intrinsically physical. For a strong statement of the immaterialist reading, see J. J. Haldane, “Aquinas on Sense-Perception," The Philosophical Review 92 (1983): 233-39. For a slightly less immaterialist reading, but one that argues that there is an immaterial (in our sense of the term) component to sensation, see S. M. Cohen, "St. Thomas on the Immaterial Reception of Forms," 193-209. For a more "physicalist" reading, see Picard, "Essai sur la connaissance sensible," pp. 15-17; Van Riet, "La théorie thomiste," pp. 389-97; Pasnau, Theories of Cognition, pp. 31-47. Picard's statement is quite accurate: "A la question posée, au sens moderne: matière ou esprit? Les scolastiques répondraient unanimement: matière." One very strong assertion of the materiality of sense can be found at Summa theologiae I, q. 12, a. 4 ad 3, where Thomas states: "Dicendum quod sensus visus, quia omnino materialis est, nullo modo elevari potest ad aliquid immateriale." Of course, his talk of a "spiritual" reception of the species or the "intentional being" of the species is potentially misleading, but as Van Riet reminds, one must understand these terms in their historical context. Accordingly, he points out the remote root of Thomas's vocabulary in Stoic, Neoplatonic, and Augustinian thought as well as its proximate source, Avicenna. What Thomas is describing is twofold: the highly changeable character of the sense power/organ and the unstable, ephemeral nature of the species itself. So, while it sounds to us like Thomas is speaking of some sort of immaterial process, in fact he is not and his language is misleading only if we forget the philosophical background that he accepts. A good example of the use of "spirit" to refer to a corporeal entity is provided by Pasnau, who quotes the ninth century thinker Costa Ben Luca: "Spirit is a kind of subtle body (corpus subtile)". (Theories of Cognition, p. 46).

16. On the perfective aspect of sensation as an immanent action, see Summa theologiae I, q. 18, a. 3 ad 1; Summa theologiae I, q. 54, a. 2 and the discussion in Owens, An Elementary Christian Metaphysics, pp. 193-95.

17. See Van Riet, "La théorie thomiste," pp. 381-82; for a discussion of the diaphanous medium, pp. 388-89.

18. Cohen ("St. Thomas on the Immaterial Reception of Forms," pp. 206-8); M. Tweedale ("Origins of the Medieval Theory that Sensation Is an Immaterial Reception of a Form," Philosophical Topics 20 [1992]: 218); and Pasnau (Theories of Cognition, pp. 39-42) all raise this question. 
So, while there is nothing intrinsic to the species in the medium that makes sensation occur in the absence of a sense organ, one must attribute the sensing to the sense power itself. It is this species in the medium that is received in the sense power; therefore, there is no need to posit any mysterious process at this point. The sense power is simply the informed organ, and because the soul, an immaterial substance, is really distinct from its powers, there is no need to think that the spiritual alteration of the sense power is a direct alteration of the soul. ${ }^{19}$ It follows that there is no reason to think that the alteration of the power is a special nonphysical event. It is simply the reception of the material species in the material power.

Thomas consistently points to the fact that the intentional reception of the species is sufficient for the occurrence of sensation; even more strongly, he has a tendency to identify sensation with the reception of the species. ${ }^{20}$ Of course, this may be all there is to the story-a suitable sensory power receiving a species results in an act of sensing. This account would well explain why Thomas rejects the need for any expressed species in the case of external sensation. ${ }^{21}$ Against this, I should make clear that I am not claiming that the identification of sensing with the reception of the species means that the sense power plays no role in the act of sensing. After all, a form received in the medium does not result in an act of sensing, so the sense power must contribute something. However, the only obvious role played by the sense power is its existence as a sense power and its nature that causes it to sense when it receives species. ${ }^{22}$

19. On the identity of organ and power, or more precisely, the claim that the organ and power make up one entity, see Van Riet, "La théorie thomiste," pp. 39697. Note that at Summa theologiae I, q. 78, a. 3, Thomas states that the "intention" of the sensible form arises in the organ.

20. Summa theologiae I, q. 14, a. 1. In addition at Summa theologiae I, q. 17, a. 2 ad 1, he states even more strongly that the affection of sense is sensation itself. See Tweedale ("Origins of the Medieval Theory," pp. 216-19) for a carefully argued view of the identity of reception/cognition. See also the strongly worded passage in Quodlibet, V, q. 2 ad 2: "Cognitio sensus exterioris perficitur per solam immutationem sensus a sensibili: unde per formam quae sibi a sensibile imprimitur, sentit." Pasnau brings a wide variety of texts to bear on this issue and concludes that Thomas does hold that the reception of the form is identical to the act of sensing (Theories of Cognition, pp. 47-60).

21. For the rejection of an expressed species in sensory cognition, see Summa theologiae I, q. 85, a. 2 ad 3; Quodlibet. q. 5, a. 9 ad 2.

22. Pasnau considers the possibility that Aquinas might hold a view to the effect that, in addition to its being a sense power, it also has a certain intrinsic dynamism that can be captured by pointing to its focusing attention on some sensible objects and not others. However, after considering passages that might lead in that direction, Pasnau correctly concludes that such a view would contradict the focus on passivity in other passages (Theories of Cognition, pp. 134-38). Burnyeat agrees: "What a very simple answer! I have the power of perception, the air around me does not. A modern reader could be forgiven for thinking it no answer at all. But within the framework of Aristotelian physics it is complete and conclusive." (Burnyeat, “Aquinas on Spiritual 
I think it is clear that Thomas's motivation in denying the formation of an expressed species by the sense power itself can be found in his concern to safeguard the directness of our sensory cognition. His problem is that, because the act of the sense power is immanent, it must terminate within the power itself. Hence, it would seem that it would have to terminate at the sensible species. Yet if the sensible species is itself a similitude, does sensation not then terminate at the likeness, rather than the sensible object itself? Thomas's way out of this potential problem is to draw a distinction between two properties of impressed species. On the one hand, one finds its properly metaphysical constitution: it is a likeness produced by the sensible form existing in the sensible object. On the other, though, Thomas wants to invoke a representational function for the impressed species. ${ }^{23}$ The thought behind this distinction is that the intentional alteration of the power brought about by the species is twofold. There is the actual coming to exist in the sense power (the entitative component) as well as its representative function (the intentional component). Only the latter properly constitutes cognition. It is clear that the species' representative function is crucial for Thomas. After all, he is insistent that the species is that by which (id quo), not that which the knower knows. ${ }^{24}$ It is only by invoking some sort of representative function of the species that such a claim could follow.

Such, in broad outline is Thomas's account of external sensation. Why does Suárez feel the need to reject it in great part? I think that Suárez's worry is twofold. First, while Aquinas provides a role for the sense power to play, Suárez believes that there is an overemphasis on the passivity of the sensory power. The passages that suggest that the reception of the species is sufficient for sensory cognition indeed leave room for the sense power to performs its acts of sensing, yet do very little to explain the nature of those acts. The sense power becomes a kind of explanatory "black box." The reception of species along with the act of the sense power produces sensory acts, but it remains unclear how we might specify the contribution sense power makes. Suárez wants to provide an account of sensation in which the contribution of the sense power is, as it were, demystified. He accomplishes this by describing those internal micro-level activities performed by the sense power. Second,

Change," p. 150). It turns out that it is not just a modern reader who thinks it is no explanation at all: so does Suárez.

23. De veritate, q. 2, a. 5 ad 17 . This distinction is usually characterized as one between the "entitative" and the "intentional" aspects of the species. For discussion, see P. E. Druin, "L'entitatif et l'intentionnel," Laval Théologique et Philosophique 6 (1950): 252-62. Note that Druin takes the intentional aspect of the species to be characterized by its "spiritual" nature. However, as we have seen, to take "spiritual" as equivalent to "immaterial" is a misreading of Thomas ("L'entitatif et l'intentionnel," pp. 159-61). Thus, to make the distinction between the being of a species and its representative function rely on the material and immaterial aspects of the species is misleading.

24. Summa contra gentiles II, 75; ST I, q. 85, a. 2; Sentencia libri De anima, lect. 8, no. 718 , among other passages. 
I think Suárez is worried that any account of sensory cognition that cannot explain what the sense power contributes on the micro explanatory level will leave itself open to the kind of charge that Lear emphasizes in his argument that some accounts of sensation do not show the transition between physical process and sensory awareness. Suárez does, as I will show, specify precisely how to understand that transition within the sensory soul itself.

Suárez, even more so than Thomas, is struck by the real parallels between intellectual cognition and sensation. Like Thomas, he accepts both the immanence of sensation as well as its apparent passivity, yet he limits the passivity of the sense power to only one "moment" of its activity and instead stresses the active character of its operation. ${ }^{25}$ Also, in agreement with Thomas, he views the sensible species as necessary so that he can avoid positing action at a distance, and he recognizes that the process by which the species is produced, communicated, and received is physical. However, he, too, is capable of using language that can mislead his reader. For example, in an early programmatic statement, he states that "every cognitive power, by the very fact that it is a cognitive, must be in some way immaterial, that is, it must be elevated above all powers that are in every way material." ${ }^{26}$ At the same time, though, he writes that the "action of the sense powers is intrinsically organic and corporeal." 27 In order to reconcile properly these two

25. Francisco Suárez, Commentaria una cum quaestionibus in libros Aristotolis De anima, ed. Salvador Castellote, 3 vols. (Madrid: Sociedad de Estudios y Publicationes [vols. 1 and 2] and Fundación Xavier Zubiri [vol. 3], 1978-1991), disp. III, q. 2, no. 16 (2:100); disp. V, q. 5 , no. 4 (2:374). Henceforth, I will cite this work as $D A$, followed by disputation, question, and paragraph. This work has a rather complicated textual history. Briefly, the Commentaria is the result of Suárez's early teaching assignment at Segovia in 1572. The work was never published in Suárez's lifetime. However, toward the end of his life, Suárez decided to rework the material for publication. He replaced the nomenclature of "disputation" and "question" with that of "book" and "chapter" and managed to rework the entire first disputation and the first six questions of the second disputation before his death in 1617. When his editor, P. Alvarez, put together the final edition of the work in 1621, he used the revised first books (based on the first eighteen questions of the early version) and the early manuscript to make a complete work. Castellote's recent critical edition of the entire early version is the one I follow here. Indeed, in order to present his theory as clearly as possible, I restrict myself to discussing the Commentary on the De anima. Thus, in effect, I am only concerned with what could be called Suárez's early account of sensation. There are at least two notable differences between the position taken in the Commentary and positions in Suárez's later works, especially the Metaphysical Disputations. I shall make a point of noting these significant differences in what follows, but shall prescind from trying to reconcile these differences or discussing what significance they might have for his later philosophical views. For the full manuscript history of the Commentaria, see Castellote's introduction to vol. 1: XXXVII-LXVIII. For a full chronological list of Suárez' writings, see M. Solana, Historia de la filosofia española, epoca del Renacimiento, vol. III (Madrid: Real Academia de Ciencias Exactas, 1941), pp. 333-40. Suárez stresses the passivity of sensation at, among other places, DA V.4.14 (2:364ff).

26. DA II.3.11 (1:176).

27. DA II.2.8 (1:156). 
assertions, one must examine the process of the production of the species itself.

Suárez unambiguously affirms that sensible species are material (materiales) and divisible (divisibiles). His striking argument is based on the axiom that an accidental form is proportioned to the power in which it exists as a subject. Sensible forms must be material, he concludes, because all sensitive powers are material and extended. ${ }^{28}$ It is noteworthy that he refers here not just to the sense organ, but to the power. After all, supporters of a nonphysical account of sensation might want to draw a distinction between the organ and the power in such a way that the physical change is in the organ, but the immaterial cognition is in the power itself. Yet Suárez's language blocks such a view. Due to the fact that the organ is the substance (substantia) and subject (subjectum) of the power, that is, it is its material cause ${ }^{29}$ the organ and the power are bound together (alligata) and the power receives its species through the organ. ${ }^{30}$ Lest this last sentence be misinterpreted to say that the power is nonmaterial, Suárez makes it clear that in contrast to the soul, which is spiritual, the sense powers are material. Indeed, they must be material because they are altered by material realities. ${ }^{31}$ One could, of course, take "material realities" here to refer to the sensible forms existing in objects; however, that would cloud the fact that alteration is properly a function of species, otherwise there would be no need for species in the first place. Like Aquinas, then, Suárez opts for a view of species and their reception that can be characterized as material in the sense mentioned earlier, that is, the species are composites of form and matter and not wholly immaterial forms.

Granted, then, the materiality of the overall picture Suárez is presenting, one must now inquire into the precise nature of the sensible species. Some of the most useful remarks on this topic can be found in the context of a discussion concerning the need for an "agent sense” power. On Suárez's

28. DA V.2.17 (2:316-18). There have been two recent articles devoted to Suárez's account of cognitive species: A. Simmons, ["Explaining Sense Perception: A Scholastic Challenge," Philosophical Studies 73 (1994): 257-75] focuses her attention on the sensible species in several sixteenth-century scholastic thinkers, while T. Rinaldi presents a more general picture of the role of the cognitive species, both sensible and intelligible ("Il problema delle "species" conoscitive nel De anima di Suárez," in A. Lamacchia, ed., La filosofia nel Siglo de Oro: Studi sul tardo Rinascimento spagnola [Bari: Levante, 1995], pp. 429-64). Older, and still valuable, studies of sensation and cognitive species in Suárez include: G. Picard, "Essai sur la connaissance sensible d'après les scolastiques," Archives de philosophie 4 (1926): 1-93; J. M. Alejandro La gnoseología del Doctor Eximio y la acusación nominalista (Comillas: Universidad Pontifica, 1948), pp. 218-42; S. C. Cubells, Die Anthropologie des Suárez (Munich: Verlag Karl Alber, 1962), pp. 111-59. There are also helpful remarks in Spruit, Species Intelligibilis: From Perception to Knowledge, vol. 2 (Leiden: E. J. Brill, 1994), pp. 297-300.

29. DA III.3.4 (2:118).

30. DA II.3.10 (1:174).

31. DA III.1.14 (2:72). 
reading, one of the reasons that thinkers posit an agent sense is because of a supposed "gap" in the process of sensation. Suárez conjectures that such thinkers must believe that the sense power is exceedingly perfect (perfecta), while the material sensible object is excessively imperfect. Such an imperfect material object could hardly be expected to act directly on a perfect sense power. Relying on the notion that the agent should be more "noble" than the recipient of the agent's action, such thinkers find it necessary to posit an agent sense that can render the imperfect sensible species fit to act on the sense power. ${ }^{32}$

Suárez replies to this line of argument by rejecting its central claim, namely, that a sensible species must be more perfect than its generating object in order to act on the sense power. He writes:

These intentional species are not more perfect than their objects, so white is a more perfect quality than its species. For each of these is a material quality, but white is perfect in its kind while its species is only a certain trace and representation of it. Indeed heat, which produces heat and a sensible species, is called "active" from the action of heat, not from the production of species. This, then, is a sign that heat is more perfect than its species. And it does not matter that the species has a greater fineness, on account of which it is called in some way "immaterial," for this fineness is a certain mode of entity along with which it remains that this entity is more imperfect according to its grade. ${ }^{33}$

So, while both the sensible quality and its species are material, the species is merely a "trace" (vestigium) and a "representation" (repraesentatio) of the object from which it arises. Rather than being more perfect than its originating object, the sensible species instead is a fine (subtilitas) entity (entitas). The use of the term "fine" here should be taken in its literal sense of "finegrained" or even "tenuous." The idea is that the species radically depends on the originating object for its existence. As such, its existence is precarious relative to that of the original sensible object. Further, by calling the species subtilitas, we are also able to capture the notion that the species is not itself sensible in any direct manner. ${ }^{34}$ Most importantly, it is because of the "fineness" of the species that they are called immaterial (immaterialis). ${ }^{35}$

In another important passage he calls impressed sensible species "imperfect participations" (imperfectae participationes) of sensible objects. He

32. DA VI.2.1 (2:470). For further information concerning the notion of an agent sense, see E. P. Mahoney, “Agostino Nifo's De sensu agente," Archiv für Geschichte der Philosophie 53 (1971): 119-42; A. Pattin, "Pour l'histoire du sens agent au moyen âge," Bulletin de philosophie médiévale 16-17 (1975-1976): 100-113.

33. DA VI.2.6 (2:474-76).

34. For the claim that we do not sense the species, see $D A$ VII.1.5 (2:556).

35. See fn. 15 above for the outline of the tradition being followed here by Suárez. The quote from Costa Ben Luca is particularly noteworthy. 
goes on to explain that species depend on their objects both for their coming to be (fieri) and their existence (esse) thereby stressing their dependence on the original object. ${ }^{36}$ In addition, he states that the very nature (ratio) of a sensible species is that it arises from the imperfection of material objects. ${ }^{37}$ All in all, the picture is pretty clear. Sensible species in the medium are material, but their materiality is of a defective, imperfect sort. Still, defective materiality is nonetheless materiality and Suárez has explicated the term "immaterial" in this context in such a way as to preserve the physicality of the species. Moreover, he has blocked the idea that sensation can function at a distance while also providing an explanation for why one cannot sense the species themselves. All of these considerations lead him to conclude that the species and the sensible form existing in the object are of different "kinds." 38 How do they differ? The sensible form exists according to the real nature itself of the quality so that the sensible form of green is itself really green. The species, however, does not exist according to the real nature of the quality, but rather exists as representative of the quality. ${ }^{39}$ This last claim is set forth in the context of Suárez's gloss of the Aristotelian claim that the sense receives its object without the matter. Yet where Thomas, following Aristotle, goes on to compare the reception of the species with the seal impressing wax, Suárez is strikingly silent about such an analogy.

The reason for his silence is important for our purposes. When the seal impresses its shape on the wax, the likeness existing between the seal and the wax is one in which they look the same, even where the matter of the seal is not passed along to the wax. The notion that species are such that they are the same shape or figure as their originating objects is, he concludes, wrong. Not only does the retina not become red when one looks at something red, the retina also does not become triangular when looking at a triangle. Consequently, Suárez holds that impressed species are qualities, but only insofar as they are dispositions. What this means is that the likeness possessed by the species is not pictorial, nor is it of the same type as the original quality itself. Instead, it is a "natural likeness" intrinsically appropriate to

36. DA VI.5.4 (2:520).

37. DA V.5.28 (2:406). While it is outside the scope of this paper to treat Suárez's physics of natural objects in any detail, it is important to note that the sensible object, like all natural agents, "multiplies" (multiplicare) its action (actio) in a circle. (DA V.2.19 [2:320]). It is this multiplication that accounts for the existence of sensible species. For more on the physics of sensible qualities and their species, see the classic work of A. Maier, "Das Problem del 'Species Sensibiles in Medio' und die neue Naturphilosophie des 14 Jahrhunderts," Freiberger Zeitschrift für Philosophie und Theologie, 10 (1963): 3-32, repr. in Maier, Ausgehendes Mittelalter II (Rome: Edizioni di Storia e Letteratura, 1967), pp. 419-51.

38. DA V.2.8 (2:306-8). Confusingly for us, Suárez says that the species and its original form differ in species. Of course the latter use of "species" refers to its logical meaning. To avoid confusion, I have used "kind" to translate this logical meaning of "species."

39. $D A$ V.2.8 (2:308-10). 
(conveniens) the originating sensible form. Consistent with his claim that the entity of the species is its representational function, this appropriateness is cashed out in terms of representation. ${ }^{40}$ The seal and wax example, then, while helpful in showing how a process can be physical and yet not involve a communication of matter, fails in describing what actually happens in the reception of the species. After all, the shape of the seal in the wax does not represent the shape of the seal itself; it is the same shape as the seal itself.

Unfortunately, Suárez does not further explicate the "intrinsic appropriateness" of the sensible species. However, we can go a long way to understanding what he has in mind by considering its role in sensory cognition. Even though he calls sensible species "formal likenesses," he rejects the thesis that species operate on the sense power by exercising formal causality. ${ }^{41}$ In fact, the species can only be an efficient cause since the mere reception of the species does not suffice for cognition. Recall that one of the unresolved issues in Thomas's account involved how the apparent sufficiency of the reception of the species failed to explain the selectivity of sensation. Now, Suárez is obviously worried about this issue and argues that were the species to act as a formal cause, its effect would have to follow immediately. Suárez takes the selectivity of sensation to be a decisive experience and argues that it follows that the species alone cannot account for cognition. Yet if the species was a formal cause, nothing else would be needed for cognition to result. ${ }^{42}$ Consequently, he concludes that the species only exercises efficient causality on the sense power and cannot account for sense cognition by itself. ${ }^{43}$

40. DA V.2.23 (2:324). Aristotle's discussion can be found at De anima II, 12 (424a18-24).

41. Suárez states that the likeness of the species is a formal likeness at $D A, \mathrm{~V}$, 2, 21 (vol. 2:322). Note that he comes to have doubts about the appropriateness of calling the sensible species a "formal likeness." Elsewhere, including the 1621 printed edition of the Commentary, Suárez explicitly rejects the assertion that impressed species are "formal likenesses." See, Book III, Chapter 2, § 26 (p. 622b): "Statutum sit ergo juxta hactenus dicta pro quarta conclusione, impressas species formales similitudines, ac veluti picturas objectorum non esse...." Note that in this passage he considers a formal likeness a kind of picture. What does not change is the fact that species are not like pictures. Apparently, Suárez came to believe that the notion of a formal likeness was "pictorial" in some basic way. In the early edition, while he uses the term "formal likeness," he has also made certain that we will not take it as pictorial.

42. DA V.2.6 (2:304). Note that Aquinas at least once suggests that the will is responsible for our not sensing objects from which one has received speciessee Summa theologiae I, q. 93, a. 6, ad 4, where Thomas distinguishes between the reception of the species, the act of sensing itself, and the act of the will engaging the act of vision in the reality seen. However, here Thomas only displaces the problem.

43. DA V.2.6 (2:306). In his An Elementary Christian Metaphysics, Owens takes this Suárezian position that the sensible species is not a formal cause to be decisive in showing the fundamental difference between Thomas and Suárez. He argues there that Thomas holds that the sensible forms in objects are the "extrinsic formal causes" of sensation insofar as they are exemplars. While he admits that the species operates 
The significance of restricting the action of the species to efficient causality is most apparent when he argues against a view that sounds rather like Thomas's. Suárez focuses his attention on what he calls the "vital reception" (vitalis receptio) theory, which has as a basic premise that the reception of the impressed species is sufficient for the act of sensation. On this theory, the act of sensation is the concomitant awareness on the part of the soul of the species received in the sense power. ${ }^{44}$ Admitting that this account has some appeal insofar as it is consistent with Aristotle's dictum that sensation is a kind of passivity, he nonetheless thinks that such a view is deeply flawed. Indeed, it implies an unacceptable account of the relation between the soul, its powers (potentiae), and its acts (actiones).

First, the impressed species cannot be identified with the act of sensation itself because this reductionist move would conflict with the position, shared by Thomas, that a cognitive act must be immanent and intrinsic. In the case of sensation, the principle of the cognitive process would be the impressed species, not the knower. Hence, the principle of cognition would be extrinsic. ${ }^{45}$ Moreover, if cognition were a mere awareness of the reception of the species, the distinction between powers and the soul itself would then be superfluous as there would be no specific function for the power to perform. This would have the consequence of making the act of sensation the proper act of the soul and yet the human soul is immaterial, and sensation would therefore be a wholly immaterial process. In addition to his commitment to the materiality of sense experience, he additionally points out that animals have sense powers, although no immaterial soul. Consequently, neither human nor animal sensation can be a proper activity of the soul itself. ${ }^{46}$ Finally, if one posits such a vital attention to the soul itself, rather than the power, the result would be to deny any real causality to the species and its originating object inasmuch as an immaterial soul cannot be affected directly by something material. It follows that there would be no point in positing species as intermediaries. Because the evidence for positing species is overwhelming, they must exercise some causality. ${ }^{47}$ This series of objections to the "vital attention" view points to the fact that the

on the sense in an efficient manner, he argues that Suárez rejects the formal extrinsic causality of the object. His conclusion is "Suarez's view makes it difficult or impossible to show that the external thing's content can undergo no change in being known." Two points are at issue here. First, of course, we see the basic agreement between Suárez and Aquinas in holding that the species operates on the level of efficient causality. Second, though, one will have to worry whether his rejection of formal extrinsic causality leads him to an account in which the thing's content can undergo change in the act of sensing (pp. 228-29, n. 14).

44. DA V.3.1 (2:340).

45. DA V.3.3 (2:344-46).

46. Suárez thinks that animal sensation and human sensation are essentially the sort of operation relying on the same powers and the same types of organs. See, DA II.2.8 (1:156); DA III.3.4 (2:118).

47. DA V.3.4 (2:346). 
sense power itself has a fundamental role to play in sensory cognition that relies on, but is not reducible to, the causal efficacy of the sensible object.

Because the species must play some causal role in sensation, as an efficient cause, but at the same time cannot be wholly responsible for the operation of the sense power, how can we more positively characterize the role of the species' reception in sense? Suárez concludes that the sensible species is only a "partially completing immediate instrument" (partialiter complens immediatum instrumentum) ${ }^{48}$ Its role is to bring the passive sense power to a higher level of actuality, while reserving to the sense power itself the actual operation made possible by the newly attained level of actuality. ${ }^{49}$ By limiting the role played by the impressed species in this way, Suárez opens up an explanatory space for the "transition," to use Lear's term, from the physical world to sensory awareness. The impressed species has, to be sure, a determinative role in the process, but we must not neglect the need for the power itself to play a crucial role. After all, it is only creatures with sense powers that can sense.

As the reception of the species is a necessary, but not sufficient condition for the act of sensation, what more is required on the part of the sense power itself? Suárez distinguishes three components of the activity of the sense power. There is the production of the act (productio), there is the reception of the act (receptio) and there is the act itself (actio) that can be considered the intrinsic end or terminus of the sense experience. In the case of vision, for example, there is the production of vision, the reception of vision and the vision itself. ${ }^{50}$ Note that the "reception" mentioned here should not be confused with the reception of the impressed sensible species. The reception of the produced act refers to the fact that the cognitive power is brought to a higher level of actuality. In other words, the act is "received" in the power as a qualitative change in the power. Hence, the produced act of cognition is itself a quality (qualitas). ${ }^{51}$

As a result, Suárez distinguishes between the production (productio) of sensation and what is produced, that is, actual sensation. The former stands at the beginning of the act of sensation while the latter is the terminus, or

48. DA V.4.16 (2:366). Picard, "Essai sur la connaissance sensible," pp. 38-41; Alejandro, La gnoseología, pp. 196-99; Cubells, Die anthropologie, pp. 112-17; and Rinaldi "Il Problemo," pp. 455-56, all correctly stress the instrumentality of the species in the context of the immanent process of sensation.

49. DA V.4.8 (2:258). W. Neidl, Der Realitäts Begriff des Franz Suárez nach den "Disputationes Metaphysicae" (Munich: Max Huber Verlag, 1966), pp. 12-17 provides a succinct account of the background for Suárez's understanding of the various levels of actuality in the process of cognition.

50. DA III.2.16 (2:100).

51. DA V.5.6 (2:376). Cf. DA III.2.16 (2:100) where Suárez states that vision itself is a quality. See Rinaldi, "Il problema," pp. 459-62 for further discussion of the notion of "actio" in Suárez. It is unclear whether Thomas agrees that cognition is a quality. For discussion, see Owens, An Elementary Christian Metaphysics, pp. 192-203, esp. at p. 194, n. 5. 
end, of the act. The production and the product are not, Suárez adds, really distinct, but only formally distinct. ${ }^{52}$ Standing behind this distinction is the simple idea that any qualitative change in a power must have a beginning and an end within the power itself. The sense power informed by the impressed species, not the species itself, is the intrinsic necessary condition of the act of sensing, while the completed act, or terminus, is the sensation. The power begins its activity once it is informed by a sensible species and when the activity is completed, sensation has taken place. So, there is only one activity, sensing, but it has a beginning and an end that, while not really separable, refer to two different aspects of the one activity.

Suárez hastens to add that the notion of terminus used here should not be understood in a material (materialiter) way, for example as a point terminates a line, but rather in an intentional, or spiritual (spiritualis) manner. By saying that the terminus is to be understood as intentional or spiritual he only means that the terminus is of a type peculiar to cognitive powers insofar as they are immanent. Explaining further, he says the relation of terminus to object is nothing other than knowing the object. The object is not represented in the image "objectively" (obiective), "as an object." $53 \mathrm{He}$ is guarding here against two potential misunderstandings. First, by using the terms "intentional" and "spiritual" to describe the terminus of the act of sensation, one might think that he is suggesting that, although the impressed species is material, the act of sensing itself is somehow immaterial. Second, one might think that to say that the sense power has an intrinsic and immanent terminus deprives the sense power of any ability to sense the external world directly and instead relies on some inferential process that leads to the sensible quality itself.

The first misunderstanding is easy enough to correct. Such an interpretation is clearly blocked insofar as Suárez takes it as axiomatic that a material power cannot elicit a spiritual act. ${ }^{54}$ From the fact that the sense power is a material power, it follows that it cannot elicit an immaterial act. Rather, one should consider the use of "spiritual" and "intentional" here as synonyms; further, one should note that "intentional" has the connotation of serving knowledge. ${ }^{55}$ Consequently, to say that one should think of the termination

52. DA V.5.4 (2:374). The notion of "formal distinction" is tricky. In essence, two items formally distinct fall short of the kind of distinction between two things (a real distinction) and yet are more distinct than the kind of distinction that holds only through the way they are considered. In brief, the distinction holds before any mental consideration of it, but the two items are not such that they exist really distinct from one another.

53. DA V.5.23 (2:394): "Ad primam difficultatem respondetur quod terminatio cognitionis ad obiectum non est materialiter intelligenda eo modo quo intelligitur terminatio linae ad punctum, sed est sumenda intentionali seu spirituali modo. Unde cognitionem terminari ad rem non est, nisi rem illam cognosci; quod potest fieri etiam si sit absens. Neque est necesse quod in imagine obiective repraesentetur."

54. DA II.3.7 (1:170).

55. DA V.1.3 (2:286). 
of the act of sensation as spiritual does not mean that sensation is some sort of immaterial process; rather, this means that it is simply the awareness of the sensible quality existing in the sensible object.

The second potential misunderstanding can be disposed of by distinguishing between sensation as a production and the act of sensation itself. The point is that the act of sensation can be viewed in two ways, namely, as it arises (in fieri) and as completed act (in facto esse). Sensation in fieri is a production (productio) that results in assimilation, that is, sensation in facto esse. Because the assimilation of the sensed object and the person sensing must take place in the sense power, the act of sensation considered as a production is a way (via) to the likeness (similitudo) that constitutes sensation, while the completed act itself constitutes the likeness (similitudo). This likeness that accounts for assimilation should not be confused with the likeness of the impressed species. The latter is merely the principle (principio) while the former is the product of the act of sensation. The completed act of sensation, then, is called a likeness simply because it constitutes the assimilation necessary in any act of sensation. ${ }^{56}$ One must, however, approach this point with particular caution. If cognition itself is a likeness, does that mean that one is directly aware of the likeness and at best only indirectly aware of the object of which the act is a likeness? Suárez emphatically denies such a theoretical consequence. After all, he is careful to state that the terminus of the act of sensation does not present the sensible object in such a way that it is represented as an object in the image produced by sensation. But if the likeness produced by the act of cognition is not what is sensed, how should it be understood? Obviously, one must consider just what it means for an act of sensation as an assimilative process to be a likeness.

A note of clarification on Suárez's vocabulary would prove helpful. He characterizes the actual assimilation in several synonymous ways. Sometimes he calls the likeness produced by the sense power a verbum, that is, literally, a word. ${ }^{57}$ Since the verbum is usually thought to be the result of an intellectual activity, Suárez is careful to stress that even in sensation, there is something like (similis) or proportional to (proportionale) a verbum produced in the act of sensing. In addition to verbum, he calls this product of the act of sensing an expressed species, opposing it to an impressed species. ${ }^{58}$ It is

56. DA V.5.27 (2:402).

57. DA V.5.9 (2:370): "Contra est, quia secundum theologos per actionem intellectus producitur verbum, quod sit terminus illius actionis; eadem autem est ratio de illa et de omnibus actionibus cognoscitivis; ergo, etc." For general background on the notion of a verbum in Suárez, see F. Riva, "La dottrina suareziana del concetto e sue fonti storiche," Rivista de filosofia neo-scolastica 71 (1979): 686-99; N. Wells, "Descartes' Idea and its Sources," American Catholic Philosophical Quarterly 67 (1993): 513-36.

58. DA V.5.16 (2:388). For another use of similis, see DA V.5.22 (2:394). For proportionale, see DA V.5.9 (2:380) and DA V.5.29 (2:406). For "expressed species," see $D A$ V. 5.17 (2:390) among many other passages. Of course, as we saw above, 
this expressed species that ultimately results from the joint activities of the impressed sensible species and the sense power. In the language above, the expressed species is nothing other than the completed act of sensing, that is, it is the quality received in the power through its productive activity. This expressed species is the counterpart on the sensory level to the concept on the intellective level. In fact, Suárez is even willing to use the term "formal concept" (conceptus formalis) to refer to the completed act of sensing. He states that, in seeing something white, the sense power forms within itself (in se format) a concept (conceptus) of the white in the object. ${ }^{59}$ So, the act of cognition as completed act, the verbum, the expressed species and the formal concept are all equivalent designations for the same thing, namely, the act of cognition as it is a quality. Another way of putting this point is to say, as Suárez does, that there is no distinction between the act of cognition as it is a quality and the expressed species. ${ }^{60}$

Stressing the potential for misunderstanding to arise in connection with his account of the expressed species, Suárez set forth the position that he does not want confused with his own. The particular worry he has involves the relation of the intrinsic terminus of cognition and the object itself. As stated above, positing such an intrinsic term might suggest that the object is seen in the expressed species. Working in favor of such a position is the authority of Thomas Aquinas. In several well-known passages in his writings, Thomas appears to say that the concept is that in which (in quo) one understands. After quoting several such passages, Suárez argues that despite such appearances, Thomas should in fact be read as teaching that the concept is the reason (ratio) for attaining to the external object itself, not the object of knowledge. Furthermore, he points out that in the Summa theologiae, Thomas never speaks of the concept as that in which one knows the

Thomas explicitly rejected the notion of an expressed species in sensation. N. Wells, ["Objective Reality of Ideas in Arnauld, Descartes, and Suárez," in The Great Arnauld and Some of His Philosophical Correspondents, ed. E. J. Kremer (Toronto: Toronto University Press, 1994), pp. 160-61, n. 16] refers to many passages in the Metaphysical Disputations that are parallel to these in the De anima.

59. $D A$ V.5.17 (2:388); $D A$ V.6.5 (2:416). Given this multiplicity of ways of speaking about the act of cognition itself, I will restrict myself whenever possible to the use of the term "expressed species." The contrast with the impressed species is readily apparent, and "expressed species, unlike many of the other terms Suárez uses to describe the act of cognition, carries with it no connotations of intellectual activity.

60. DA V.5.15 (2:386): "Igitur verbum neque est species impressa, neque aliquid distinctum ab actu intelligendi; est ergo ipse actus." Also see DA V.5.5 (2:374-376). For some interesting remarks on the identity of the act of cognition and the expressed species, as well as its implications for early modern philosophy, see N. Wells, "Objective Reality of Ideas in Arnauld, Descartes, and Suárez," pp. 138-83. For a more favorable assessment of Suárez's point, see Rinaldi, "Il problema," pp. 46264. For the scholastic background of the identification, see F. Riva, "La dottrina suareziana del concetto e sue fonti storiche," pp. 694-99. 
object and indeed explicitly repudiates such a view. ${ }^{61}$ Consequently, he sees himself as following Thomas's teaching when arguing that the product of the act of sensation is not that in which we see the objects of sensation. In fact, if one views objects in their expressed species, it would be equivalent to what occurs when one views objects in a mirror, that is, one would not be seeing the objects directly, but only by a means that is itself sensible. ${ }^{62}$ If the expressed species is not a likeness in the sense of an image in which one sees the object, what kind of likeness is it?

First, it must be noted that sense powers have a natural order toward their proper objects, namely, the sensible qualities existing in sensible objects. These sensible objects are the finis qui insofar as they are the natural end of the sense powers. The role of the expressed species is to be an intrinsic terminus within the power and it can best be described as a finis quo-the intrinsic end by which the proper end is achieved. ${ }^{63}$ In this way, Suárez is able to deny that the act of sensing is simply a matter of being aware of the expressed species. Rather, it functions both as the internal product of the act of sensation and as that by which (quo) one senses the object. ${ }^{64}$ In brief, the production of the act of sensation and the expressed species it produces lead us to a sensing of the sensible object. It is how one attains to the object itself. Consequently, despite the many intervening steps between the object and the act of sensing, it is really the object that one attains when sensing.

Having clearly distinguished between the reception of the sensible species and the production of the act of sensation, Suárez needs to provide an account of the relation between these two activities. Most importantly, he has described both the impressed and expressed species as likenesses (similitudines), but the necessity for two likenesses in sensory cognition is not immediately apparent. What links the two species, impressed and expressed is that they both function in order to represent the sensible object. Indeed, Suárez explained that the two species do not differ in their mode of representing (in modo repraesentandi). ${ }^{65}$

When discussing the impressed species, Suárez was clear that the representation involved no essential unity on the ontological level between it

61. $D A$ V.5.18 (2:390) and DA V.5.23 (2:396). The passages of Thomas that he cites include De veritate, q. 4, a. 2, ad 2; De potentia, q. 9, a. 5; and the Commentary on the Gospel of John, lectio 1. The passage in the Summa theologiae that he points to is I, q. 85, a. 2. For a recent consideration of the relation between the prior passages and the Summa theologiae passage, see L. Dewan, O.P., "St. Thomas and Pre-conceptual Intellection," Etudes Maritainiennes/Maritain Studies 11 (1995): 220-33. Dewan argues that in fact Thomas changes his mind between these earlier texts and the latter, and emphasizes, as does Suárez, that the language of "in quo" is conspicuous by its absence in the Summa theologiae.

62. DA V.5.2 (2:372).

63. For the distinction between "finis qui" and "finis quo," see DA II.2.2 (1:152).

64. DA III.2.16 (2:100).

65. DA V.5.13 (2:394-96). 
and the original quality in the object insofar as the species is merely a trace of the original sensible form and is of a different type. ${ }^{66}$ This claim amounts to the fact that the eye does not need to be impressed with green in order to see green. Instead, all that is required is that somehow the green object communicates itself through the medium and into the power in such a way that the power can be caused to see the green object as green. As noted above, though, the mere reception of the species is not thereby sufficient in the way it would be if green formally communicated itself through its species. Now, if the expressed species does not differ in its manner of representing, that just means that there does not have to be green in us in order to sense a green object. Moreover, if there were green inside of us, it would impede our ability to sense green objects. The expressed species, it follows, must be a natural likeness intrinsically agreeing with the original sensed quality without possessing that quality itself. It is by reason of the impressed species, which arises from the sensible object, that the power is able to produce a similitude of the object and this is nothing other than the act of sensation. Therefore it is impossible for the power to produce a better similitude as such (ut sic) than the impressed species. ${ }^{67}$

I take it that in pointing out that the two species do not differ in their mode of representation and that the expressed species is not a better likeness than the impressed species, Suárez is ruling out any possibility that the act of sensation adds something in the process of sensing. Once again, the main point is that neither the impressed nor the expressed sensible species blocks our direct access to the sensible qualities themselves. The impressed species is not itself sensed and has no essential unity with the sensible quality itself and so in no way interferes with the direct sensing of external sensible qualities. Moreover, by making the likeness produced in the sense power the very act of sensation, Suárez safeguards the directness of the act of sensing.

66. $D A$ V.2.13 (2:312): "Unde dicitur quod similitudo in essendo requirit unitatem specificam, tamen similitudo repraesentativa minime id exigit." A. Simmons states "the species nonetheless retains an identity in essence and definition with that quality and is therefore still a genuine similitude of that sensible quality which exists naturally in the object" ("Explaining Sense Perception," p. 267). This remark is a bit strong, I believe in light of the fact that the species and the original quality differ in kind. Such a difference clearly implies that they must be essentially different; there is nothing red about the species of a red quality. However, the natural agreement may suggest some sort of unity via the representative function of the species. The reason that the species of red causes us to sense red is because the species just is the sort of thing that can represent the red quality. Picard goes too far in the other direction when he states that intentional species are only simple determinants of the faculty ("Essai sur la connaissance sensible," p. 40). Alejandro echoes this remark in La gnoselogía [p. 198]). Such claims seem to leave out the representative nature of the sensible species. Still, to say that there is a natural agreement is a far cry from saying that they are identical in essence.

67. DA V.5 (2:384): "nam si intellectus habet virtutem ad producendum aliquam similitudinem obiecti, est ratione speciei imprassae ab obiecto . . . ergo impossibile est quod producat meliorem similitudinem ut sic quam sit ipsa species." 
One is not first aware of some internal representation prior to the sensing of external sensible qualities.

Despite this agreement in the way of representing common to both the impressed and expressed species, there are several differences between them. The impressed species is produced by the sensible quality itself, while the expressed species is produced by the sense power. Also, the two species play different functional roles in the complete process of sensation. The impressed species is the partial efficient cause of the act of sensing while the expressed species (the act of sensing) is the intrinsic terminus of the production of the act of cognition. So one can distinguish the following steps in the process of sensory cognition:

Presuppositions:

1) The sensible object communicates its "likeness" throughout the medium in the sensible species, a material entity with no essential unity with the object itself.

2) The material sense power structured so as to be affected by sensible species.

Components of the act of sensing:

1) The reception of an impressed species by a sense power.

2) The activity of the sense power itself in producing its own act of sensation.

a) The use by the power of the impressed species as an intrinsic beginning point (sensation in fieri).

b) The production of the expressed species (sensation in facto esse $=$ verbum $=$ sensation itself ).

The two big changes made by Suárez in Thomas's theory, then, involve the type of causality exercised by the species and the role of the sense power itself. He is frequently criticized for both changes. In both cases, the charge amounts to a decreasing commitment to realism in the perceptual process. ${ }^{68}$ However, I think the criticisms fail to do justice to Suárez's position. First, the claim that the species acts only efficiently on the sense combined with the additional premise that the species and its originating quality are of a different type might lead one to conclude that the species can misrepresent the object. Of course, he admits that sensory error is possible, but that is only because either the medium or the sense power becomes corrupted thereby impeding the species in its representative function. The standard example is the way that an ill person will taste something sweet as sour. The species is not misrepresenting, but the power is not receiving the species properly. ${ }^{69}$

68. See Owens, An Elementary Christian Metaphysics, and fn. 43 above. Druin, "L'entitatif et l'intentionnel," pp. 311-13.

69. Suárez's account of sensory error is rather brief. See $D A, 6.3$ (2:494-501). 
Moreover he unequivocally states that "All sense powers are ordered to having a perfect cognition of sensible objects."70 It seems pretty clear that sense powers just are naturally well functioning and issues of skepticism in sensory cognition are rather remote from Suárez's central concerns.

There is a slightly more problematic issue in his account of error. Since the impressed species depends on its object only as an efficient cause, and since God can take the place of any efficient cause, by the absolute power of God (potentia absoluta Dei), it is possible that God could conserve in the eye an impressed species of something not present. The result would be that the eye would see something as present that in fact is not present. By way of an example Suárez asks his reader to imagine a mirror present to the eyes. Grod could make it that a species of Peter, who is in Rome, exist at the mirror. The species would then be reflected into the eye and the power of sight would see Peter existing in Rome and consequently would see something absent, but would judge it to be present. Suárez goes on and extends this example to include a case where Peter does not even exist. What is interesting here is that Suárez claims that such visions of Peter would be abstractive (abstractiva) and not intuitive (intuitiva), that is, the vision would be of objects that are absent and not present. The impressed species that God would produce in such a situation would be true (vera); however, one would see through these impressed species to something that is not present. ${ }^{71}$ In this case, then, the species is truly misleading since it makes us see something as present that in fact is absent. Yet, as Suárez sets forth this example, it is clear that he is just worrying about a logical possibility. Just because God can so conserve a species, it does not follow that he does so. Indeed, the whole thrust of his account of sensation shows its essential veridicality.

Finally, just because the species is of a different type than the original quality is no reason to cast suspicion on it. All that is necessary is that it represent in the organ/power the original quality and there is no reason to think that a representation of a quality need share anything other than the natural agreement that Suárez mentions. It, in fact, need only be whatever kind of physical impression is necessary to allow the sense power to act. The same consideration is applicable to the expressed species as well. It need only be whatever kind of qualitative change is necessary in the sense power/organ that causes a person to be aware of the sensible qualities in things. Again, it seems most reasonable that such a quality bear no formal conformity with the original quality. Otherwise, one would have no way to avoid the conclusion that what one is seeing is the internal representation

70. DA III.3.14 (2:138). Notice how this separates him from Descartes for whom sensory cognition of secondary qualities is utterly confused. For Descartes, see Principles of Philosophy IV, a. 200 (AT VIII-1, 323-24) and the discussion in M. Wilson, "Descartes on the Perception of Primary Qualities," in Essays on the Philosophy and Science of Rene Descartes, ed. S. Voss (Oxford: Oxford University Press, 1993), pp. 162-76.

71. DA VI.5.6 (2:524). 
of the external object. Hence, encoded in the impressed species is all the representational content that is required for the act of sensing and this explains why the representation of the expressed species is no more of a likeness than the original impressed species.

Turning now to the second objection to Suárez's account, the claim that the sense power might add something to the content of the expressed species, I think that this objection is misguided as well; however, to show this I will have to resort to some speculation. Remember that what must be explained in a theory of sensation is the "leap" between purely physical processes and full sensory awareness trying not to reduce the latter to the former. By stressing the role played by the sense power in cognition, he resists Thomas's language of passivity in favor of a more robust, but potentially misleading, idiom. What exactly does the sense power do? It senses. How? Through its own resources informed by the species. Since sensation is both a physical and intentional action, and since the reception of form without matter is a physical action, sensation must be more than the mere reception of the species. Both authors thus argue that, in addition to any physical action of the species, there is a representative function as well. Aquinas holds that the reception of this representative content is sufficient for sense cognition while Suárez rejects that supposition. Although Suárez never explicitly states it, he must hold that the representational content of the species is not such as to be "transparent." This is, it seems to me, a boon for his account. If the representational content were transparent, one would be open to the charge that what one senses simply is the species, not the external sensible form. The power of a theory of sensation revolving around species, after all, consists in explaining why objects are not directly sensible at a distance.

A species theory explains, that is, what internal representations are necessary to be able to sense that which cannot, literally, come to exist within a person. The point implicit in talking of intentional being is supposed to prevent one from having to say that the sensible quality comes to exist in a person in the exact same way it exists in the external world. If one then makes it that the species is all that is necessary for cognition, the species has simply been substituted for the external sensible form. Instead, by arguing that the representational content is not such as to be immediately operative on the sense power, Suárez safeguards the directness of sense cognition. There is no way that the species can be sensed by the sense power because, by itself the species is not sensible. An additional benefit of making the species opaque in this manner involves being able to explain the selective attentiveness of sensation. Not every species causes sensation and if, in fact, some activity of the sense power is required, we can understand why this is the case. The sense power must, to extend the metaphor, render the opacity of the sensible species transparent. It performs this operation in the very act of sensing by producing the completed act of sensing based on the opaque likeness contained in the sensible species. However, it does not add anything to the species; nor does it sense the species. It senses the external 
sensible quality through the sensible species. The expressed species is the transparent flipside of the impressed species, but at the same time it is also the act of sensation.

In conclusion, then, I have tried to show that Suárez's account of external sensation is best understood against a thomistic backdrop. Only by recognizing the similarities to Thomas (the rejection of action at a distance, the physicality of the sensory process) can we understand the philosophical thrust of his position. Throughout, Suárez maintains the physicality of sensation while refusing to reduce sensation to the reception of the sensible species in the sense power. However, in refusing this reductive strategy, Suárez commits himself to a corresponding understanding of the representational role of the species as well as the operation of the sense power itself. Unlike Thomas, he tries to shed some light on the microprocesses occurring inside the "black box" of the sense power. Finally I have shown that in rejecting key components of the thomistic account, most notably by claiming that the sense produces an expressed species, Suárez does not thereby reject a direct realist account of sensation. One really does sense external sensible qualities as they are, and this is done through the expressed sensible species. At no time does one sense internal representations. 